\title{
Simultaneous entry of oxygen ions originating from the Sun and Earth into the inner magnetosphere during magnetic storms
}

\author{
Y. Ebihara, ${ }^{1}$ S. Kasahara, ${ }^{2}$ K. Seki, ${ }^{3}$ Y. Miyoshi, ${ }^{3}$ T. A. Fritz, ${ }^{4}$ J. Chen, ${ }^{4}$ \\ M. Grande, ${ }^{5}$ and T. H. Zurbuchen ${ }^{6}$ \\ Received 2 February 2009; revised 23 March 2009; accepted 30 March 2009; published 28 May 2009.
}

[1] The aim of this paper is to present, for the first time, almost simultaneous enhancements of both low- and high-charge-state oxygen ions in the inner magnetosphere during magnetic storms. Storm-time enhancements of low-charge-state O ions are well recognized, but the behavior of high-charge-state $\mathrm{O}$ ions is less known. Data simultaneously collected from the ACE, Geotail, and Polar satellites indicate the following: (1) In the inner magnetosphere (at $L=3-5$ ), the number density of high-charge-state $\mathrm{O}$ ions was increased during the early phase of magnetic storms (Polar). (2) No corresponding enhancements were identified in the number density of $\mathrm{O}$ ions observed in the solar wind (ACE) and the near-Earth magnetotail (Geotail). (3) The number density of high-charge-state $\mathrm{O}$ ions present in the near-Earth magnetotail was considerably lower than in the solar wind and the inner magnetosphere. We calculated trajectories of $\mathrm{O}^{6+}$ ions under electric and magnetic field models. The $\mathrm{O}^{6+}$ ions that became observable in the energy window of Polar were transported from the high-latitude magnetopause to the inner magnetosphere when the convection electric field was strong. When the convection electric field was weak, the ions were reflected toward the distant tail. The $\mathrm{O}^{6+}$ ions that became observable in the energy window of Geotail were sufficiently transported from the low-latitude magnetopause to the near-Earth magnetotail regardless of the strength of the convection electric field. The observational facts may be adequately explained in terms of ion transport paths depending on the convection electric field with different entry points.

Citation: Ebihara, Y., S. Kasahara, K. Seki, Y. Miyoshi, T. A. Fritz, J. Chen, M. Grande, and T. H. Zurbuchen (2009), Simultaneous entry of oxygen ions originating from the Sun and Earth into the inner magnetosphere during magnetic storms, J. Geophys. Res., 114, A05219, doi:10.1029/2009JA014120.

\section{Introduction}

[2] Oxygen is the third most abundant element in the solar system [e.g., Lodders, 2003]. Oxygen present in the Earth's atmosphere escapes from its gravity potential in the form of singly or doubly charged $\mathrm{O}$ ions. The escape rate is of the order of $10^{25}-10^{26} \mathrm{~s}^{-1}$, depending on geomagnetic and solar activities [e.g., Yau and André, 1997]. Low-chargestate $\mathrm{O}$ ions are present almost all over the magnetosphere. During magnetic storms, low-charge-state $\mathrm{O}$ ions are largely responsible for the energy density of ions in the inner

\footnotetext{
${ }^{1}$ Institute for Advanced Research, Nagoya University, Nagoya, Japan.

${ }^{2}$ Institute of Space and Astronautical Science, Japan Aerospace Exploration Agency, Sagamihara, Japan.

${ }^{3}$ Solar-Terrestrial Environment Laboratory, Nagoya University, Nagoya, Japan.

${ }^{4}$ Center for Space Physics, Boston University, Boston, Massachusetts, USA.

${ }^{5}$ Institute of Mathematical and Physical Sciences, University of Wales, Aberystwyth, UK.

${ }^{6}$ Department of Atmospheric, Oceanic and Space Sciences, University of Michigan, Ann Arbor, Michigan, USA.
}

Copyright 2009 by the American Geophysical Union. 0148-0227/09/2009JA014120 magnetosphere (ring current) [e.g., Gloeckler et al., 1985; Krimigis et al., 1985; Hamilton et al., 1988; Daglis et al., 1999a, 1999b].

[3] Oxygen present in the Sun is ionized at its surface, and heated from $\sim 1 \mathrm{eV}$ to $\sim 1 \mathrm{keV}$ in the corona [e.g., Lie-Svendsen and Esser, 2005]. It is then released into the interplanetary space as solar wind. Solar wind $\mathrm{O}$ ions are present in the form of high-charge-state $\mathrm{O}$ ions, in particular, $\mathrm{O}^{6+}$ ions [e.g., Henke et al., 1998, and references therein], so that it can be used for a good tracer of solar origin ions. High-charge-state $\mathrm{O}$ ions are found in the magnetosheath [Gloeckler et al., 1986], the low-latitude boundary layer [Eastman et al., 1990], and the outer magnetosphere [e.g., Gloeckler et al., 1985; Kremser et al., 1987; Christon et al., 1994]. The charge state ratio between $\mathrm{O}^{6+}$ and $\mathrm{O}^{7+}$ ions present in the outer magnetosphere is in good agreement with the ratio in the solar wind, with a lag of $\sim 6-8 \mathrm{~h}$ or more [Christon et al., 1998], indicating the direct entry of $\mathrm{O}$ ions from the solar wind into the outer magnetosphere. In the magnetosphere, $\mathrm{O}$ ions are subjected to a charge exchange process with exospheric neutral $\mathrm{H}$ atoms [Spjeldvik and Fritz, 1978; Kremser et al., 1987; Christon et al., 1994]. The existence of $\mathrm{O}^{3+}$ and $\mathrm{O}^{4+}$ ions, which are thought to 

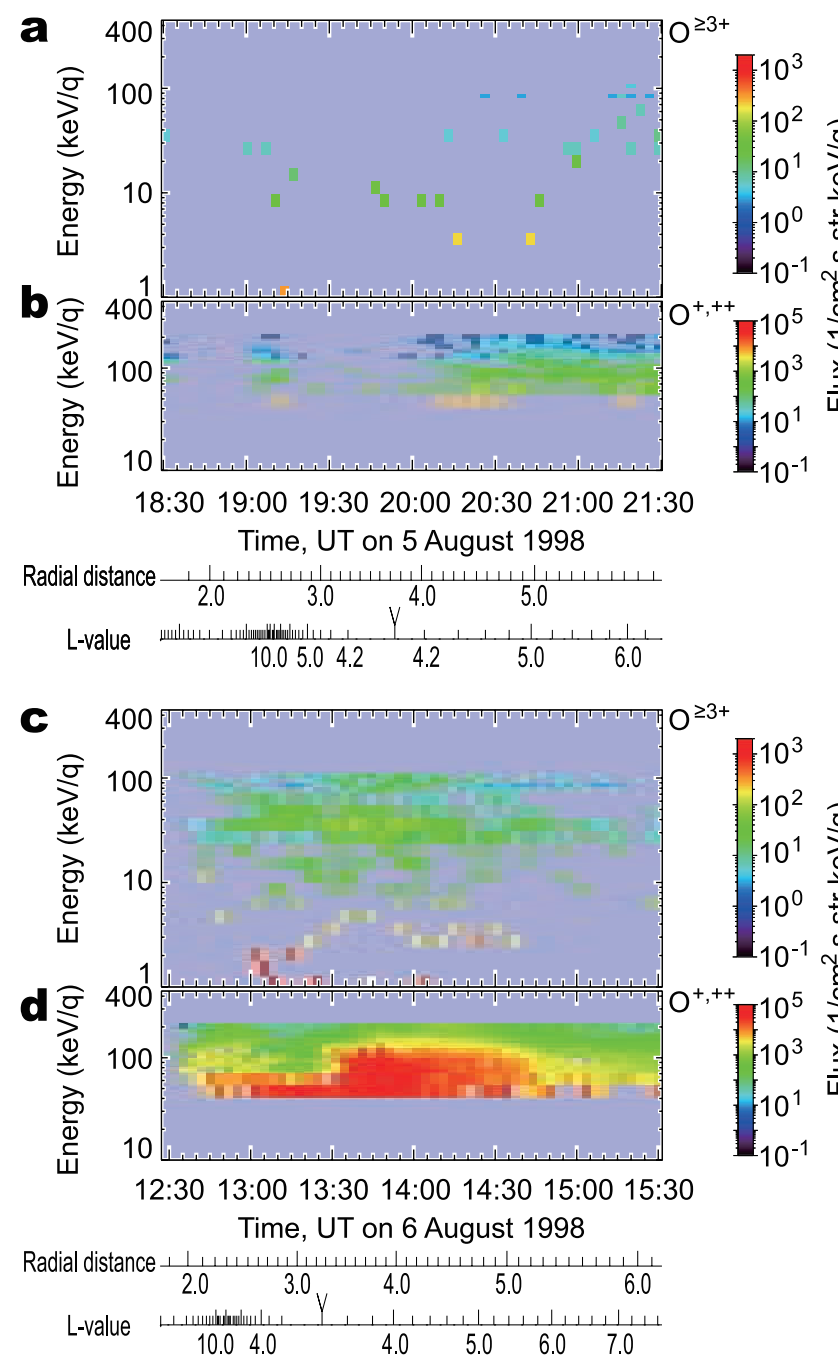

Figure 1. Spectrograms of energy per charge $(\mathrm{keV} / \mathrm{q})$ versus time in universal time (UT) of spin-averaged $\mathrm{O}$ ion fluxes measured by the Polar satellite located in the inner magnetosphere ( $a$ and $b$ ) before and ( $c$ and $d$ ) during a magnetic storm. (a and c) $\mathrm{O}^{\geq 3+}$ ions; ( $b$ and $d$ ) $\mathrm{O}^{+,++}$ions. Orbital information of the radial distance and $L$ value in Earth radii is indicated at the bottom of the spectrogram.

be the secondary product of $\mathrm{O}^{5+}, \mathrm{O}^{6+}$, and $\mathrm{O}^{7+}$ ions, is suggested to be a direct indication that $\mathrm{O}$ ions can undergo charge exchange [Kremser et al., 1987; Christon et al., 1994].

[4] To the best of our knowledge, only a few papers have been published on the concentration of high-charge-state $\mathrm{O}$ ions in the inner magnetosphere at $L<5$, where $L$ is McIlwain's L parameter. For example, Gloeckler et al. [1985] have shown the existence of $[\mathrm{C}+\mathrm{N}+\mathrm{O}]^{\geq 3+}$ ions at $L>3$. Kremser et al. [1987] have reported that the flux of $\mathrm{O}^{6+}$ ions increases with $L$ in the range $L=5-7$. However, it was decreased to levels below the sensitivity threshold of an ion analyzer at $L<5$. Therefore the behavior of high-chargestate $\mathrm{O}$ ions at $L<5$ (in the inner magnetosphere, or the heart of the ring current) is less known.

[5] Ion composition data obtained from the ACE, Geotail, and Polar satellites help in understanding transport processes of high-charge-state $\mathrm{O}$ ions from the solar wind to the inner magnetosphere. Our study focuses on the magnetic storms that occurred in August-September 1998, during which the Polar satellite intersected the equatorial plane on the nightside at $L=3-5$, and the Geotail satellite traversed the nearEarth magnetotail on the nightside at 9-23 Re. The ACE satellite observed $\mathrm{O}$ ions in the solar wind at $\sim 240-249 \mathrm{Re}$ upstream of the Earth. Note that several coronal mass ejections (CMEs) hit the Earth's magnetosphere during the period of interest.

[6] This paper is organized as follows. Section 2 presents observations of $\mathrm{O}$ ions simultaneously acquired by the Polar, Geotail, and ACE satellites in the inner magnetosphere, in the near-Earth plasma sheet, and in the solar wind, respectively. Section 3 describes trajectory tracing and its results. Reconstructed fluxes of $\mathrm{O}$ ions are compared with the satellite observation. Section 4 discusses (1) the origin of the $\mathrm{O}$ ions observed by the satellites, (2) transport processes of high-charge-state $\mathrm{O}$ ions, (3) transport processes of lowcharge-state $\mathrm{O}$ ions, (4) behavior of $\mathrm{O}$ ions in the inner magnetosphere, and (5) behavior of $\mathrm{O}$ ions in the near-Earth plasma sheet. Section 5 concludes on the observation and calculation.

\section{Observation}

[7] Data collected from the Polar satellite using a magnetospheric ion composition spectrometer (MICS) [Wilken et al., 1992; Roeder et al., 2005] was used to calculate the number density of $\mathrm{O}^{+,++}$and $\mathrm{O}^{\geq 3+}$ ions present in the inner magnetosphere. The Polar satellite was launched in 1996 into a highly elliptical polar orbit with an apogee of approximately $9 \mathrm{Re}$, a perigee of approximately $1.8 \mathrm{Re}$, and an orbital period of approximately 18 hours. Data obtained from the ACE satellite using a solar wind ion composition spectrometer (SWICS) and a solar wind ion mass spectrometer (SWIMS [Gloeckler et al., 1998]) were used to determine the number density of $\mathrm{O}$ ions present in the solar wind. Data obtained from the Geotail satellite using a suprathermal ion composition spectrometer (STICS [Williams et al., 1994]) were used to determine the number densities of $\mathrm{O}^{6+}$ and $\mathrm{O}^{+}$ions present in the near-Earth magnetotail. The STICS instrument measures the ions in an energy range of 9.27-214.6 keV/q.

[8] Figure 1 shows an example of the spectrograms of $\mathrm{O}^{+,++}$and $\mathrm{O}^{\geq 3+}$ ion fluxes acquired by Polar/MICS in the inner magnetosphere before and during a magnetic storm. The storm commenced at $\sim 00$ UT on 6 August 1998. The Dst index reached its minimum of $-138 \mathrm{nT}$ at $11 \mathrm{UT}$ on 6 August 1998. The energy range of $\mathrm{O}^{+,++}\left(\mathrm{O}^{\geq 3+}\right)$ ions from $40 \mathrm{keV} / \mathrm{q}$ to $200 \mathrm{keV} / \mathrm{q}$ (1 keV/q to $100 \mathrm{keV} / \mathrm{q})$ is well suited for determining the major energy component present in the inner magnetosphere. The spacecraft traversed the inner magnetosphere on the nightside at $\sim 04$ MLT. Prior to the magnetic storm, fluxes of the $\mathrm{O}^{+,++}$and $\mathrm{O}^{\geq 3+}$ ions were as low as the sensitivity threshold of the instrument (Figures $1 \mathrm{a}-1 \mathrm{~b})$. In the next orbit, the Polar satellite traversed the equatorial plane at almost the same MLT and $L$. The fluxes of both the $\mathrm{O}^{+,++}$and $\mathrm{O}^{\geq 3+}$ ions were substantially increased by 2 orders of magnitude in comparison with the previous orbit (prestorm condition) as shown in Figures $1 \mathrm{c}-1 \mathrm{~d}$. 


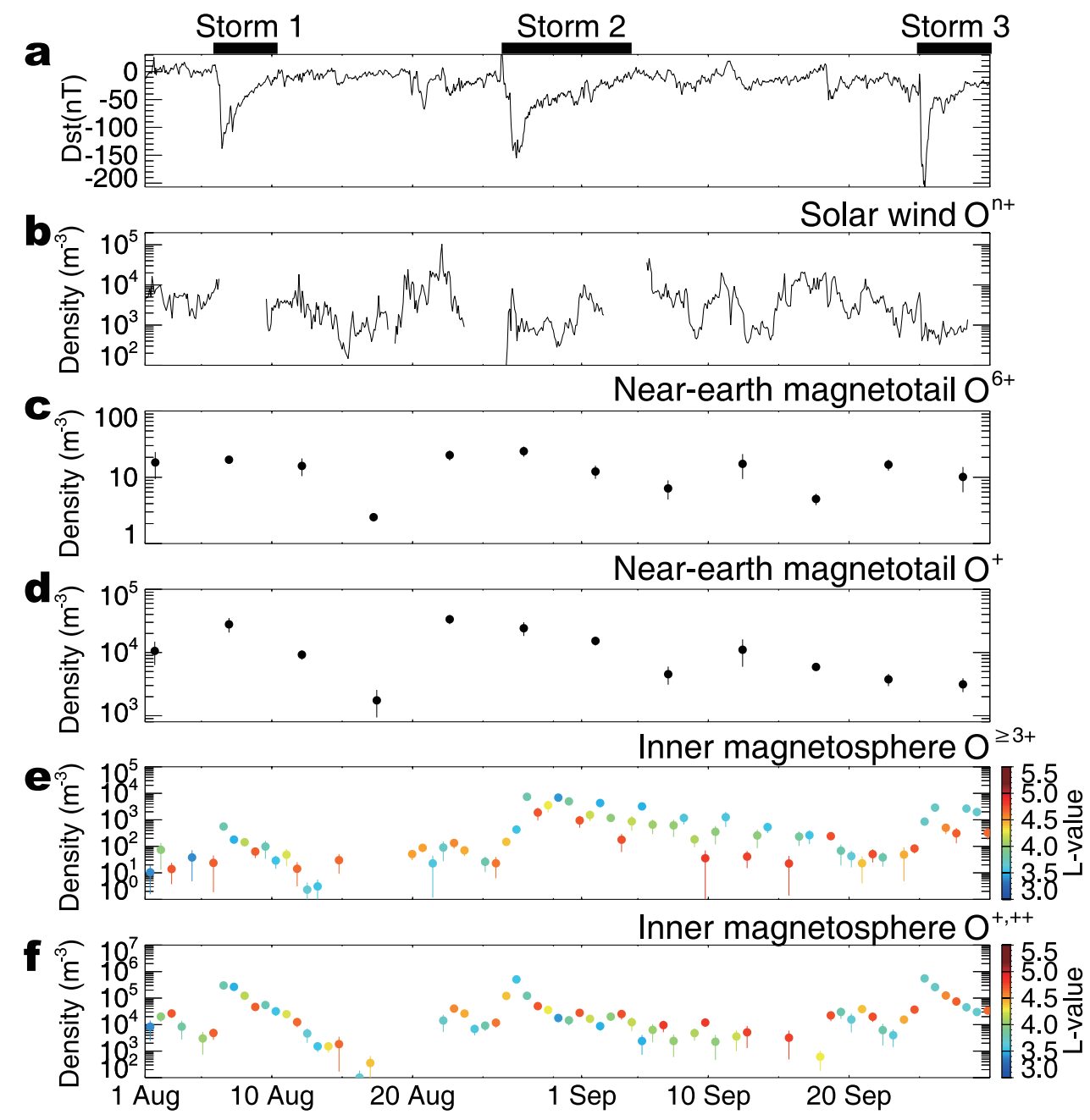

Figure 2. (a) Dst index. (b) Number density of solar wind O ions measured by the ACE satellite at $\sim 240-249$ Re upstream of Earth. (c) Averaged number density of $\mathrm{O}^{6+}$ ions measured by the Geotail satellite at $\sim 9-23 \mathrm{Re}$ on the nightside in the near-Earth magnetotail. (d) Same as Figure 2c except for $\mathrm{O}^{+}$ions. (e) Averaged number density of $\mathrm{O}^{\geq 3+}$ ions measured by the Polar satellite located near the equatorial plane at $L=3.5-5.0$ at MLAT $\leq \pm 10^{\circ}$. (f) Same as Figure $2 \mathrm{e}$ except for $\mathrm{O}^{+,++}$ions. The color code indicates the $L$ value of the Polar satellite in Re. Large magnetic storms are indicated by solid horizontal bars.

[9] Figure 2 summarizes the number densities of lowand high-charge-state $\mathrm{O}$ ions observed in the solar wind (Figure 2b), near-Earth magnetotail at $\mathrm{R}=9-23 \mathrm{Re}$ (Figures $2 \mathrm{c}$ and $2 \mathrm{~d}$ ), and inner magnetosphere near the nightside equatorial plane at $L=3.5-5.0$ (Figures $2 \mathrm{e}$ and $2 \mathrm{f})$. The Dst index is shown in Figure 2a. Three magnetic storms with a minimum Dst of less than $-100 \mathrm{nT}$ are identified, which are roughly indicated by solid horizontal bars. Hereinafter, the three storms are referred to as Storm 1, 2 , and 3 , respectively. In Figures $2 \mathrm{c}$ and $2 \mathrm{~d}$, the number density is obtained by averaging over the time interval during which Geotail traversed the near-Earth magnetotail from dusk to dawn. In Figures $2 \mathrm{e}$ and $2 \mathrm{f}$, the number density is derived by averaging over the time interval during which the Polar satellite situated near the equatorial plane within \pm 10 MLAT, with an assumption that all the $\mathrm{O}^{\geq 3+}$ ions consist of $\mathrm{O}^{6+}$. At least five features are identified as listed below.
[10] 1 . The number density of $\mathrm{O}^{\geq 3+}$ ions was markedly increased in the inner magnetosphere during an early phase of the storms (Figure 2e).

[11] 2. The number density of $\mathrm{O}^{+,++}$ions was also increased in the inner magnetosphere during an early phase of the storms (Figure 2f).

[12] 3. The variation of the number density of $\mathrm{O}^{\geq 3+}$ ions in the inner magnetosphere (Figure 2e) was apparently independent of the number density of $\mathrm{O}$ ions in the solar wind (Figure 2b) and that of $\mathrm{O}^{6+}$ ions in the near-Earth magnetotail (Figure 2c).

[13] 4. The number density of $\mathrm{O}^{6+}$ ions in the near-Earth magnetotail (Figure 2c) was lower than those of $\mathrm{O}$ ions in the solar wind (Figure $2 \mathrm{~b}$ ) and $\mathrm{O}^{\geq 3+}$ ions in the inner magnetosphere (Figure 2e).

[14] 5. The number density of $\mathrm{O}^{6+}$ ions in the near-Earth magnetotail (Figure 2c) is fairly correlated with that of $\mathrm{O}^{+}$ ions (Figure $2 \mathrm{~d}$ ). The number density of $\mathrm{O}^{+}$ions was $\sim 2$ 


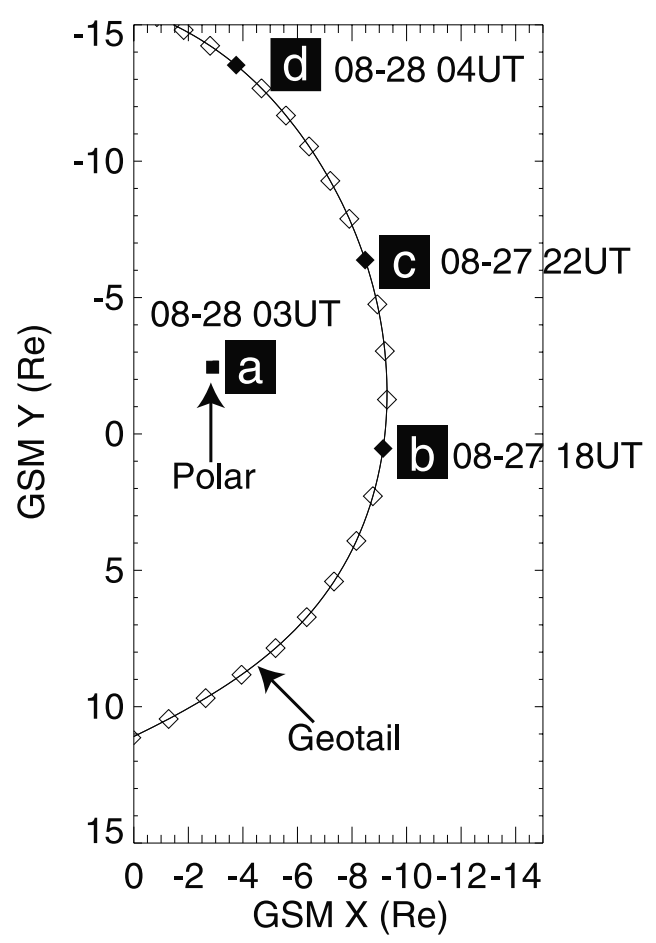

Figure 3. Positions of the Geotail and Polar satellites in the $x-y$ plane in the GSM coordinates.

orders of magnitude larger than that of $\mathrm{O}^{6+}$ ions, which is consistent with a result of the previous observation carried out in the outer magnetosphere [e.g., Kremser et al., 1987].

\section{Trajectory Tracing}

[15] We focus on Storm 2 that occurred on 26-28 August 1998, during which the Polar and Geotail satellites traversed the nightside magnetosphere at almost the same time. We selected three positions of the Geotail satellite at which the Geotail satellite was located at $\sim 00$ MLT, $\sim 03$ MLT and $\sim 05$ MLT. The Polar satellite intersected the equatorial plane at $L \sim 4$ at $\sim 03$ MLT. The selected positions of the satellites are summarized in Table 1 in detail, and displayed in Figure 3 in the GSM $x-y$ plane.

[16] We carried out trajectory tracing backward in time using empirical magnetic field and electric field models in order to find possible entry points and paths of high-chargestate $\mathrm{O}$ ions observed by the Polar and Geotail satellites. The time-dependent convection electric field was determined by the Weimer 2000 empirical model [Weimer,

Table 1. Positions Used as Starting Points of the Backward Trajectory Tracing

\begin{tabular}{cccccc}
\hline Label & Satellite & $\begin{array}{c}\text { Radial } \\
\text { Distance } \\
(\text { Re })\end{array}$ & $\begin{array}{c}\text { MLT } \\
(\text { hours })\end{array}$ & $\begin{array}{c}\text { MLAT } \\
\left({ }^{\circ}\right)\end{array}$ & $\begin{array}{c}\text { Time } \\
(\text { UT) }\end{array}$ \\
\hline a & Polar & 3.9 & 0242 & 0.0 & 03 on 28 August 1998 \\
b & Geotail & 9.2 & 2346 & -18.9 & 18 on 27 August 1998 \\
c & Geotail & 10.6 & 0229 & -6.3 & 22 on 27 August 1998 \\
d & Geotail & 14.3 & 0458 & 11.7 & 04 on 28 August 1998 \\
\hline
\end{tabular}

2001] together with the corotation electric field. The magnetic field was determined by the Tsyganenko 1996 model [Tsyganenko, 1995; Tsyganenko and Stern, 1996] together with the dipole field. The solar wind parameters summarized in Figure 4 were imposed on the empirical convection electric field model. The solar wind parameters were extracted from the 1-hour averaged OMNI database [King and Papitashvili, 2005]. The propagation time from the satellite to Earth's magnetosphere was adjusted. As for the magnetic field, we imposed time-dependent parameters presented in Figure 4 on the Tsyganenko 1996 model. That is, we used time-dependent electric and magnetic field models. Induction fields are not included. The tilt angle with respect to the solar ecliptic plane was assumed to be 0 to reduce the computing cost.

[17] Trajectories of $\mathrm{O}^{6+}$ ions were tracked backward in time from the four positions summarized in Table 1 until they reached one of the following boundaries; the magnetopause defined by the Tsyganenko 1996 model, the distant tail located at a radial distance of 50 Re downtail from the center of the Earth, and the surface of the Earth. The initial speed $\left|\mathbf{V}_{\mathrm{i}}\right|$ was divided into 30 sections with $\Delta\left|\mathbf{V}_{\mathrm{i}}\right|=133 \mathrm{~km} / \mathrm{s}$, the pitch angle was divided into 36 sections, and the gyrophase was divided into 2 sections. In total, 2160 source particles were traced backward in time for a given satellite position summarized in Table 1. Once the ions encountered the magnetopause, the phase space density of ions was mapped from the magnetopause to the original position, that is, the satellite position. Refer to the paper published by Ebihara et al. [2006] for detailed explanation on trajectory tracing.

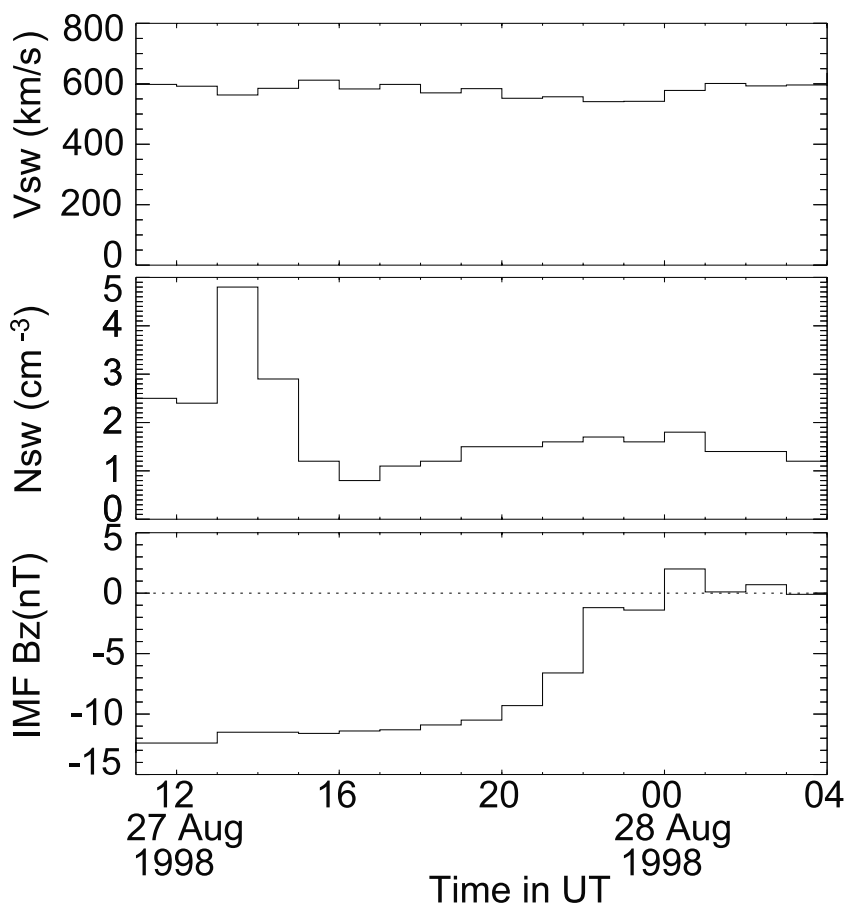

Figure 4. (top) Solar wind velocity, (middle) solar wind density, and (bottom) $z$ component of the IMF (IMF Bz) measured by the Wind satellite. The propagation time from the Wind satellite to Earth's magnetosphere is adjusted. 


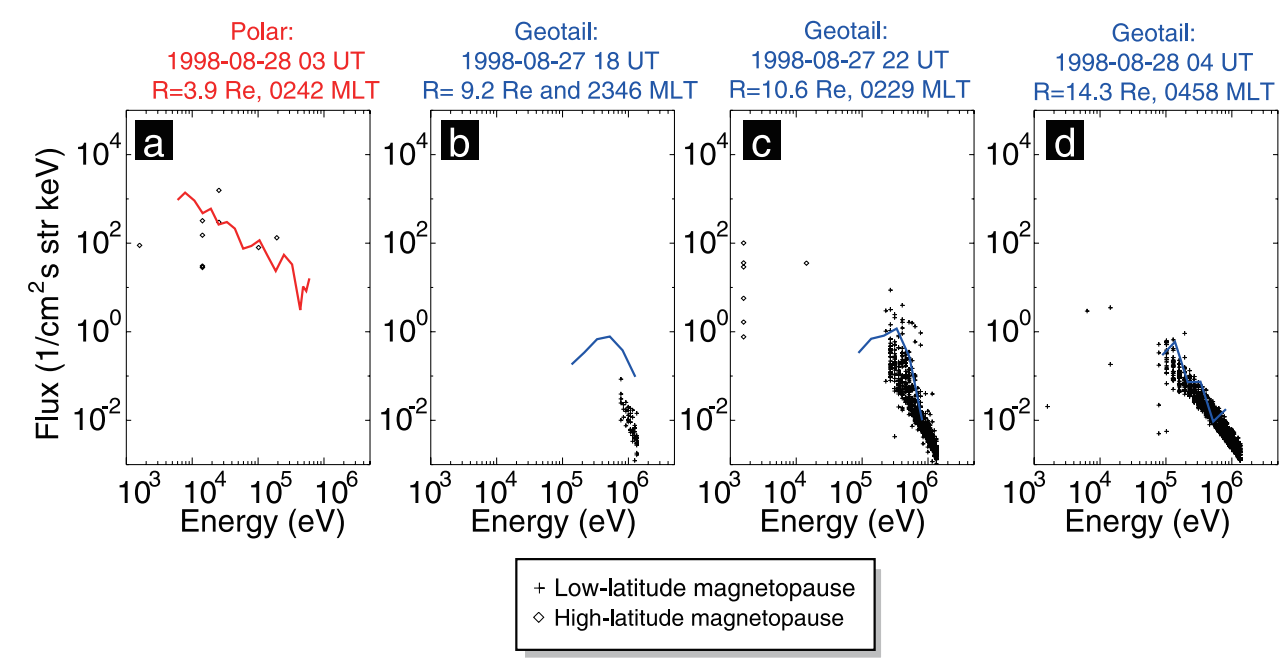

Figure 5. Reconstructed differential number flux of $\mathrm{O}^{6+}$ ions at the positions of the Polar satellite labeled as $a$ (see Figure 3 and Table 1) and the Geotail satellite labeled as $b, c$, and $d$. The plus sign represents the low-latitude magnetopause origin, while the diamond-shaped symbol represents the highlatitude magnetopause origin. The blue line indicates the flux of $\mathrm{O}^{6+}$ ions, as observed by the Geotail satellite. The red line indicates the flux of $\mathrm{O}^{\geq 3+}$ ions, as observed by the Polar satellite with an assumption that they are dominated by $\mathrm{O}^{6+}$ ions.

[18] The phase space density of $\mathrm{O}^{6+}$ ions at the magnetopause was calculated from the drifting $\kappa$ distribution, which is given as follows

$$
f(E)=N\left(\frac{m}{2 \pi \kappa E_{c}}\right)^{3 / 2} \frac{\Gamma(\kappa+1)}{\Gamma(\kappa-1 / 2)}\left(1+\frac{E^{*}}{k E_{c}}\right)
$$

where $N$ is the density, $m$ is the mass, $E_{c}$ is the characteristic energy, and $E^{*}=m\left|\mathbf{V}-\mathbf{V}_{0}\right|^{2} / 2$, where $\mathbf{V}$ is the velocity and $\mathbf{V}_{0}$ is the bulk velocity of the particle [Baumjohann and Treumann, 1997]. From the ACE observation of $\mathrm{O}^{6+}$ ion density presented in Figure $2 \mathrm{~b}, N$ is assumed to be $0.01 \mathrm{~cm}^{-3}$. The other parameters such as $E_{c}$ and $\kappa$ were chosen to fit the Geotail observation that was carried out near the dawnside magnetopause; $E_{c}$ of $1 \mathrm{keV}$ and $\kappa$ of 2.5. $\mathbf{V}_{0}$ was assumed to be $(-593,0,0) \mathrm{km} / \mathrm{s}$. In the highlatitude magnetopause or the mantle (where $\mid$ GSM Z $\mid \geq$ $10 \mathrm{Re}$ and $0 \geq \mathrm{GSM} X \geq-50 \mathrm{Re}$ ), $\mathbf{V}_{0}$ was assumed to be half that of $\mathbf{V}_{0}$ in the magnetosheath, that is, $(-297,0,0) \mathrm{km} / \mathrm{s}$ [Rosenbauer et al., 1975]. We also assumed that the solar wind $\mathrm{O}^{6+}$ ions were directly penetrated into the magnetosphere. This assumption can be justified by the in situ measurement of $\mathrm{O}^{6+}$ ions reported by Eastman and Christon [1995]. They have shown that $\mathrm{O}^{6+}$ ions tend to be systematically transported from the magnetosheath to the outer magnetosphere. For this particular study, it is our intention to determine accessibility of $\mathrm{O}^{6+}$ ions from the magnetopause to the satellite positions, rather than to estimate their phase space density at the satellite positions.

[19] Figure 5a shows the calculated fluxes (diamondshaped symbol) together with the flux observed by the Polar satellite in the inner magnetosphere (red line). The calculation result demonstrates that $\mathrm{O}^{6+}$ ions were certainly transported from the magnetopause to the position of the Polar satellite. The source region is determined to be the high-latitude magnetopause. A slight disagreement in flux between the observation and calculation is probably attributed to the assumed phase space density at the high-latitude magnetopause, and the electric and magnetic field models. Since no observational data on the concentration of ions near the high-latitude magnetopause is available for this particular period, we cannot solve this disagreement.

[20] Figures $5 \mathrm{~b}-5 \mathrm{~d}$ show the calculated fluxes (diamondshaped symbol, or plus sign) together with the fluxes observed by the Geotail satellite in the near-Earth magnetotail (blue line). At $R=9.2 \mathrm{Re}$ and $2346 \mathrm{MLT}$ (Figure 5b), ions with energy $>770 \mathrm{keV}$ are found to come from the lowlatitude magnetopause as indicated by a diamond-shaped symbol. It is interesting to note that the low energy cutoff of the high energy part at approximately $770 \mathrm{keV}$ nearly corresponds to the peak of the flux observed by the Geotail satellite. At $R=10.6 \mathrm{Re}$ and 0229 MLT (Figure 5c), the low energy cutoff of the high energy part of the ions is decreased to $\sim 230 \mathrm{keV}$, nearly corresponding to the peak of the observed flux. There appears to be a slight contribution from the low energy ions $(<14 \mathrm{keV})$ coming from the high-latitude magnetopause as indicated by a plus sign. The energy gap between $14 \mathrm{keV}$ and $230 \mathrm{keV}$ is caused by ions that come from the distant tail where no particle source is assumed. Since the low energy limit of Geotail/STICS is $\sim 57 \mathrm{keV}$ for $\mathrm{O}^{6+}$ ions, we cannot confirm the existence of the low energy part of the ions. A mixture of ions from the high-latitude boundary and the low-latitude boundary has been suggested by Ashour-Abdalla et al. [1997], although they traced $\mathrm{H}^{+}$ ions. At $R=14.3 \mathrm{Re}$ and 0458 MLT (Figure 5d), the low energy cutoff of high and major energy part is decreased to $\sim 78 \mathrm{keV}$. The existence of the cutoff energy probably explains the Geotail observation that the number density of $\mathrm{O}^{6+}$ was significantly smaller than in the solar wind.

[21] Some selected trajectories of $\mathrm{O}^{6+}$ ions are shown in Figure 6. On the left-hand side, trajectories of $\mathrm{O}^{6+}$ ions leaving the high-latitude magnetopause with initial energy of $5 \mathrm{keV}$ are shown. The thick line indicates the one 

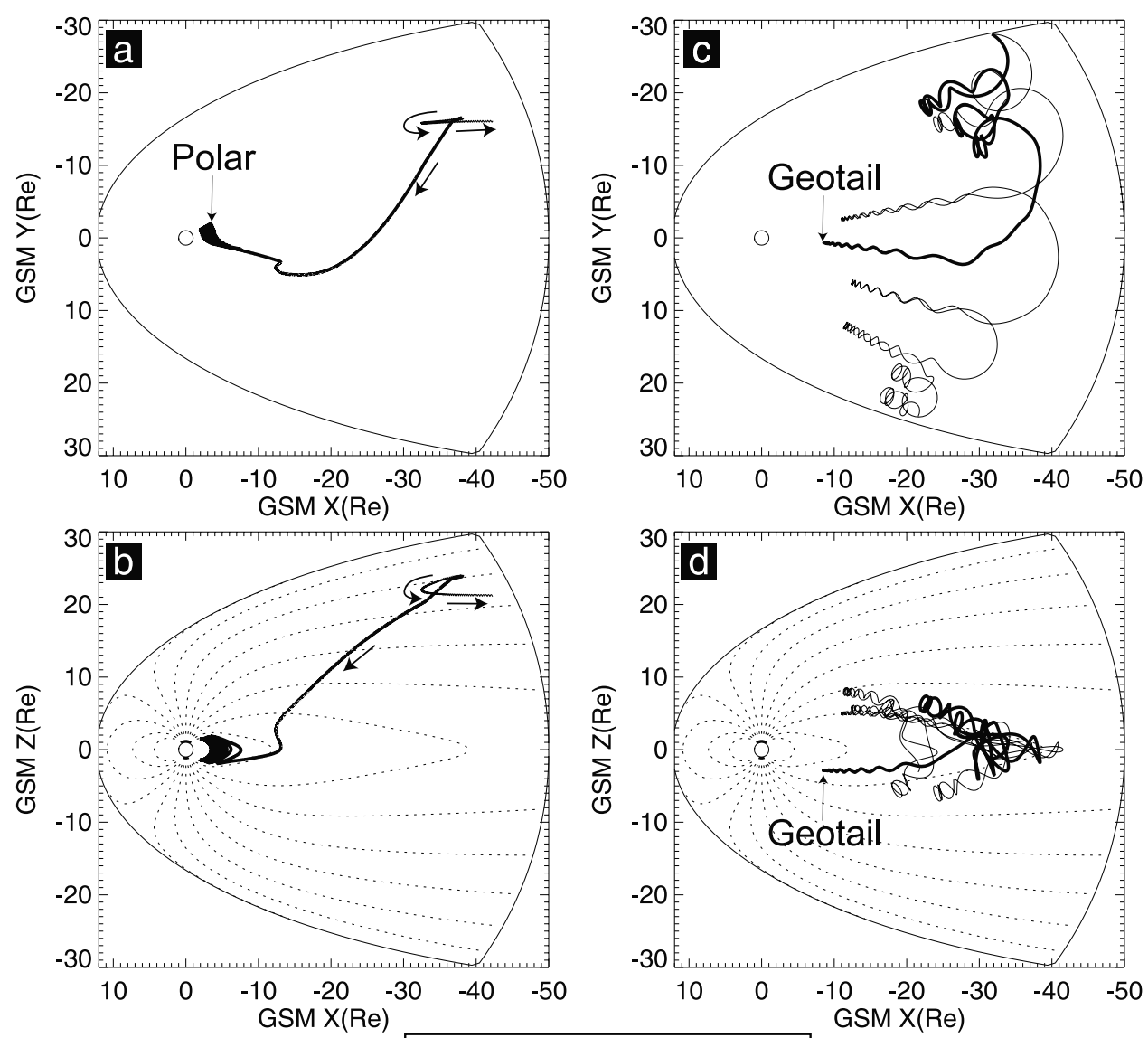

\begin{tabular}{l}
- Time-dependent convection \\
Weak convection \\
\hline
\end{tabular}

Figure 6. Example of trajectories of $\mathrm{O}^{6+}$ ions in the (top) $x-y$ plane and (bottom) $x-z$ plane in the GSM coordinates. A thick line indicates the trajectory of the ion under the time-dependent electric and magnetic fields. A thin line stands for the trajectory under the condition of 03 UT on 28 August 1998, that is, weak convection electric field. Magnetic field lines are indicated by dotted lines in the bottom panels.

calculated under the realistic, time-dependent electric and magnetic fields. It took 6.2 hours to travel from the magnetopause to the position of the Polar satellite (label $a$ in Figure 3). Thus the ion experienced a strong convection electric field during the period when IMF was southward (between $\sim 21$ UT on 27 August 1998 and $\sim 00$ UT on 28 August 1998). The thin line represents the one calculated under the condition of 03 UT on 28 August 1998 at which IMF is northward and the convection electric field is relatively weak. The ion is reflected in the high latitude lobe region toward the distant tail due to the mirror force. The trajectories are shown to be quite different from each other.

[22] On the right-hand side of Figure 6, trajectories of $\mathrm{O}^{6+}$ ions leaving the low-latitude magnetopause with initial energy of $680 \mathrm{keV}$ are shown. Because the kinetic energy is relatively high, the ion experienced grad-B and curvature drifts together with nonadiabatic acceleration near the current sheet where the gyroradius of the ion is comparable to the curvature radius of a field line. Finally, the ion reached the position of the Geotail satellite (label $b$ in Figure 3). It took only 7.2 minutes to complete the travel. When the convection electric field was held constant to be weak, the ion also experienced grad-B and curvature drifts, and tracked a similar trajectory. The influence of the convection electric field on the $\mathrm{O}^{6+}$ ions observed by Geotail seems to be relatively small.

[23] Figure 7 is the same as Figure 5 except that the $\mathrm{O}^{6+}$ ions were calculated under the condition of 03 UT on 28 August 1998 at which IMF is northward and the convection electric field is weak. As shown in Figure 7a, no ions reached the position of the Polar satellite because the ions were reflected in the high latitude lobe region toward the distant tail. In Figures $7 b-7 d$, the ions are shown to reach the positions of the Geotail satellite.

[24] Figure 8 shows the aerial view of the determined entry points of $\mathrm{O}^{6+}$ ions that reached the positions of the Polar satellite (red sphere) and the Geotail satellite (blue sphere). The green surface represents the assumed boundary; the magnetopause and the distant tail. A majority of the entry points of the ions that reached the Polar satellite are concentrated in the high-latitude magnetopause, whereas a majority of those of the ions that reached the Geotail satellite are primarily concentrated in the low-latitude magnetopause on the dawnside. It is speculated that the low-latitude (high-latitude) magnetopause is probably the 


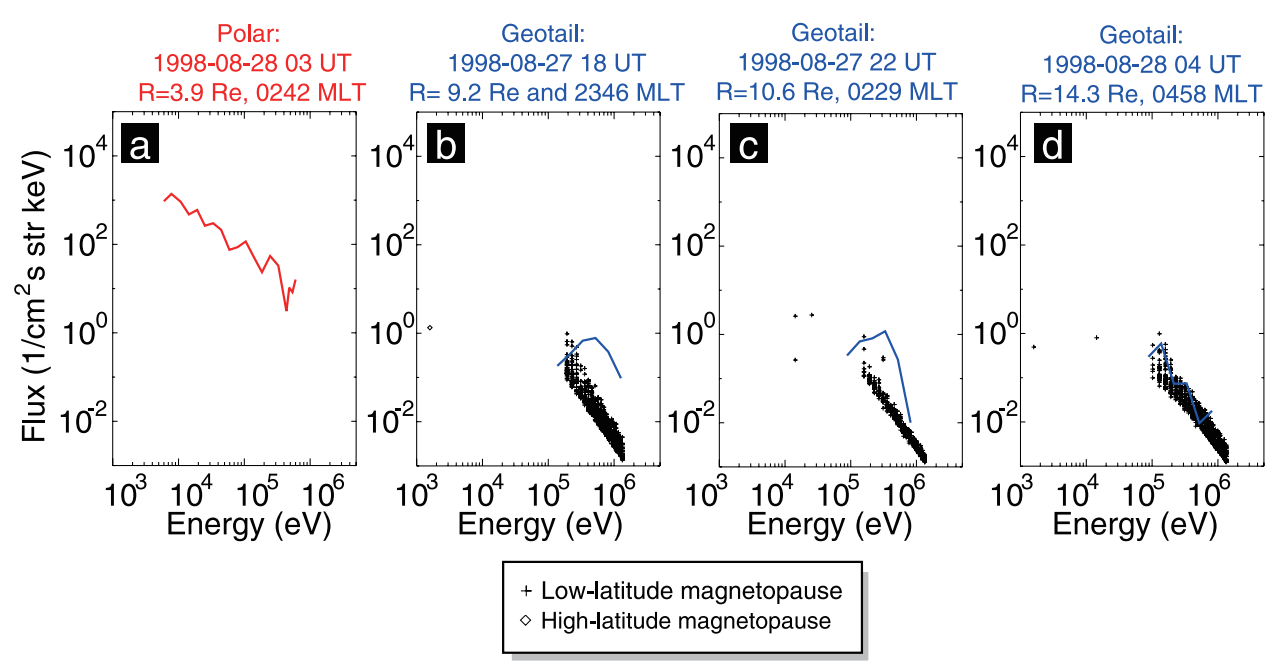

Figure 7. Same as Figure 5 except that the trajectories of $\mathrm{O}^{6+}$ ions were calculated under the condition of 03 UT on 28 August 1998 at which IMF is northward and the convection electric field is weak.

sufficient source of the high-charge-state $\mathrm{O}$ ions that became observable by the Geotail satellite (Polar satellite). The distant tail is also identified to be a major source region. To the best of our knowledge, no phase space density of $\mathrm{O}^{6+}$ ions in the distant tail has been reported. We intend to avoid introducing the distant tail as a source region until a reliable phase space distribution of $\mathrm{O}^{6+}$ ions in the distant tail is derived.

\section{Discussion}

\subsection{Origin of Observed $O$ Ions}

[25] O ions are subjected to charge gain (electron loss) and charge loss (electron capture) with exospheric neutral
$\mathrm{H}$ atoms [Spjeldvik and Fritz, 1978]. Since the number density of $\mathrm{O}^{+,++}$ions is at least 2 orders of magnitude higher than that of $\mathrm{O}^{\geq 3+}$ ions, enhanced $\mathrm{O}^{+,++}$ions are most likely of the Earth origin, and they are not the secondary product (charge loss) of $\mathrm{O}^{\geq 3+}$ ions. With an estimated cross section for a charge gain of $\sim 10^{-20} \mathrm{~m}^{2}$ at $100 \mathrm{keV}$ [Spjeldvik and Fritz, 1978] and the density of the exospheric neutral $\mathrm{H}$ atom of $\sim 2 \times 10^{8} \mathrm{~m}^{-3}$ at geocentric distance of $4 \mathrm{Re}$ [Rairden et al., 1986], we estimated the characteristic time of the charge gain to be 5.3 days, which is significantly longer than that required to suddenly increase the number density of $\mathrm{O}^{\geq 3+}$ ions. This indicates that the sudden increase in the number density of $\mathrm{O}^{\geq 3+}$ ions in the inner magnetosphere is most likely attributed to the sudden

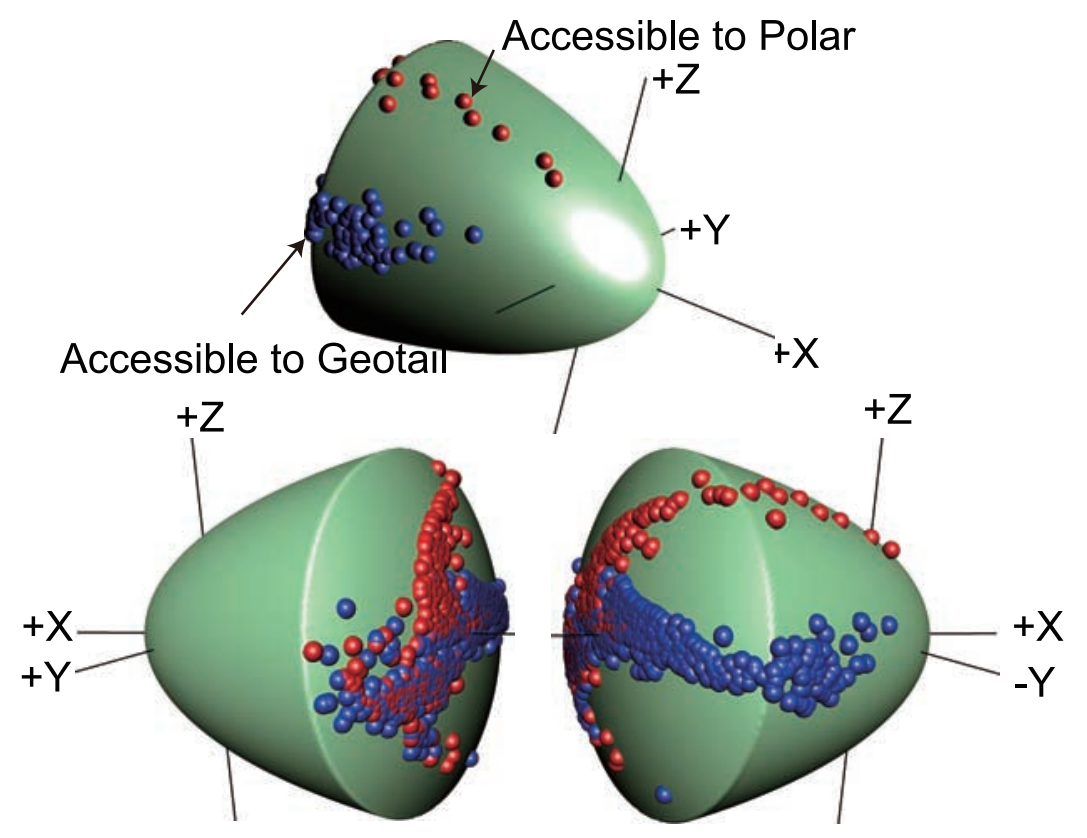

Figure 8. Determined entry points of $\mathrm{O}^{6+}$ ions that are accessible to the position of the Polar satellite (red sphere) and that of the Geotail satellite (blue sphere). The green surface represents the modeled outer boundary; the magnetopause, and the distant tail. 
penetration of $\mathrm{O}^{\geq 3+}$ ions from the solar wind into the magnetosphere, and not the charge gain of the Earthoriginating $\mathrm{O}$ ions. Therefore the $\mathrm{O}^{\geq 3+}$ and $\mathrm{O}^{+,++}$ions observed by the Polar satellite are thought to originate from the Sun and the Earth, respectively.

\subsection{Transport of High-Charge-State $O$ Ions}

[26] During the three storms, the number density of highcharge-state $\mathrm{O}$ ions was not significantly increased in the near-Earth magnetotail, whereas that was suddenly increased in the inner magnetosphere. This difference in behavior can be explained by either or both the following reasons. First, Geotail/STICS could not detect the major energy component of high-charge-state $\mathrm{O}$ ions in the near-Earth magnetotail. Second, a large number of high-charge-state $\mathrm{O}$ ions were almost directly supplied from the magnetopause into the inner magnetosphere.

[27] From the results of trajectory tracing, it is found that the $\mathrm{O}^{6+}$ ions originating from the high-latitude magnetopause can reach the position of the Polar satellite at $L=3.9$, which sufficiently explains the Polar observation of highcharge-state $\mathrm{O}$ ions. When the convection electric field is weak, the $\mathrm{O}$ ions originating from the high-latitude magnetopause tend to be reflected toward the distant tail, and they cannot reach the position of the Polar satellite (see Figures $6 \mathrm{a}$ and $6 \mathrm{~b}$ ). The $\mathrm{O}^{6+}$ ions originating from the low-latitude magnetopause can reach the position of the Geotail satellite in the near-Earth magnetotail independent of the convection electric field. These calculation results clearly explain the results of the Polar and Geotail observations; that is, the Polar satellite observed the enhancement of $\mathrm{O}^{\geq 3+}$ ions in the inner magnetosphere during the magnetic storms, whereas the Geotail satellite observed $\mathrm{O}^{6+}$ ions in the near-Earth magnetotail with its concentration independent of the storms. The enhancement of the large-scale convection electric field may play an important role in transporting the $\mathrm{O}$ ions from the magnetopause to the inner magnetosphere.

[28] Previously, intense high-charge-state $\mathrm{O}$ ions have been observed by Polar/MICS in the polar cap including the cusp region [e.g., Chen et al., 1997; Fritz et al., 2003]. The charge state of $\mathrm{Fe}$ ions observed in the cusp/cleft region is found to be correlated well with that observed in the solar wind [Perry et al., 2000], indicating a direct entry of solar wind material into the cusp/cleft region. The cusp is suggested to trap energetic charged particles because of its geometry [e.g., Sheldon et al., 1998; Pugacheva et al., 2005]. In addition, energetic particles trapped in the cusp are suggested to be a source of the magnetospheric particles, and vice versa [Antonova, 1996; Blake, 1999; Delcourt and Sauvaud, 1999; Antonova et al., 2000; Sandahl, 2003; Chen et al., 2005; Zuluaga et al., 2006; T. A. Fritz et al., Is the cusp a source or a sink for magnetospheric energetic particles?, paper presented at International Symposium: From Solar Corona Through Interplanetary Space, Into Earth's Magnetosphere and Ionosphere: Interball, ISTP Satellites, and Ground-Based Observations, Kyiv, Ukraine, pp. 205-209]. Thus the cusp is thought to be one of the potential source regions of the high-charge-state $\mathrm{O}$ ions observed by Polar in the inner magnetosphere. However, we could not clearly identify the cusp source of the $\mathrm{O}^{6+}$ ions by carrying out trajectory tracing as shown in Figure 8. Possible explan- ations are that ions originating from the cusp was actually unable to reach the position of the Polar satellite, and/or that the number of tracked ions was insufficient to find the cusp source in the calculation.

[29] Shimazu and Tanaka [2005] traced the trajectories of solar energetic $\mathrm{H}^{+}$ions $(\geq 100 \mathrm{keV})$ under electric and magnetic fields obtained by carrying out a global magnetohydrodynamics simulation. They suggested that the shock drift acceleration at Earth's bow shock affects the entry of $\mathrm{H}^{+}$ions into the inner magnetosphere. The number of $\mathrm{H}^{+}$ ions that reach the inner magnetosphere increase with the solar wind pressure. Therefore it is speculated that the entry process of the solar wind $\mathrm{O}$ ions is not so simple, and it is probably influenced by many factors.

[30] In the inner magnetosphere, the maximum density of $\mathrm{O}^{\geq 3+}$ ions observed during Storm 1 was smaller than during the other storms, while the maximum density of $\mathrm{O}^{+,++}$was almost the same as that during the other storms. All these storms were caused by CMEs, and the later two storms were accompanied with SSC (sudden storm commencement) due to the interplanetary shock driven by sheath in front of magnetic clouds. Some acceleration processes associated with the interplanetary shock may efficiently result in subsequent density enhancement of high-charge-state $\mathrm{O}$ ions in the inner magnetosphere during the latter two storms.

[31] We cannot exclude the possibility that the solar wind ions entered the distant magnetotail, and penetrated deep into the inner magnetosphere under the convection electric field [e.g., Kavanagh et al., 1968] because we did not track the trajectories at $>50$ Re. Christon et al. [1994] calculated bounce-averaged trajectories of high-charge-state heavy ions, including $\mathrm{O}$ ions, and succeeded to explain the penetration of the heavy ions from the near-Earth magnetotail into the inner magnetosphere at $L \sim 6-7$ in terms of the enhanced convection electric field. Grande et al. [1996] have shown that the CRRES satellite observed heavy ions, such as $\mathrm{Fe}, \mathrm{Mg}$, and $\mathrm{Si}$, at $4 \leq L \leq 7$ during the intense storm of 24 March 1991. After tracing trajectories of equatorially mirroring ions, they suggest that ions of recent solar origin in the magnetotail had rapid access to the position of the CRRES satellite in the inner magnetosphere under the strong convection electric field. Both their and our calculations involve the strong convection electric field, but the suggested paths are different from each other. To reach a definitive conclusion, more realistic magnetic field and electric field models are obviously needed.

\subsection{Transport of Low-Charge-State $O$ Ions}

[32] The number density of low-charge-state $\mathrm{O}$ ions in the inner magnetosphere during storms is known to be suddenly increased [e.g., Gloeckler et al., 1985; Hamilton et al., 1988; Daglis et al., 1999a, 1999b]. The characteristic energy of the low-charge-state $\mathrm{O}$ ions in the inner magnetosphere is of the order of tens of $\mathrm{keV}$ [Krimigis et al., 1985], while the typical temperature at the topside of the ionosphere is of the order of $1 \mathrm{eV}$. Some models have been developed to "bridge" the energy gap between the topside ionosphere and the inner magnetosphere [e.g., Cladis, 1986; Delcourt et al., 1990; Daglis et al., 1999b; Moore and Horwitz, 2007, and references therein]. Daglis et al. [1999b] have suggested that a large-scale convection electric field as well as substorm processes may play an important role in 
increasing the number density of Earth-originating ions present in the inner magnetosphere. The number density of $\mathrm{O}^{+,++}$ions in the inner magnetosphere was significantly increased during the storms (see Figure 2f), whereas that of $\mathrm{O}^{+}$ions in the near-Earth magnetotail was not always increased during the storms (see Figure 2d). This difference in the behavior of $\mathrm{O}^{+}$ions may be explained by either or both the following two reasons. First, Geotail/STICS could not detect the major energy component in the near-Earth magnetotail. Second, a major portion of $\mathrm{O}^{+}$ions was directly supplied from the ionosphere into the region between the Polar and Geotail satellites. However, this is beyond the scope of this study.

\subsection{Behavior of $O$ Ions in the Inner Magnetosphere}

[33] Figures $2 \mathrm{e}$ and $2 \mathrm{f}$ show the number densities of $\mathrm{O}^{\geq 3+}$ and $\mathrm{O}^{+,++}$ions obtained by the Polar satellite near the equatorial plane on the nightside. The ion density tends to vary over a period of $\sim 72$ hours, especially during Storm 2 . The $L$ value at which the Polar satellite intersects the magnetic equatorial plane depends on the tilt angle of the Earth's magnetic axis and UT. The period of 72 hours is attributed to the least common multiple of the orbital period of the Polar satellite (18 hours) and the rotation period of the Earth (24 hours). The density variation with a period of 72 hours is most likely attributed to a spatial variation, rather than a temporal variation. If this was the case, during Storm 2, the density of $\mathrm{O}^{\geq 3+}$ ions would be higher at a small $L$ value than at a large $L$ value, whereas that of $\mathrm{O}^{+,++}$ions would be lower at a small $L$ value than at a large $L$ value. As for $\mathrm{O}^{+,++}$ions, the dependence of the density on the $L$ value can be explained in terms of the charge exchange loss with neutral $\mathrm{H}$ atoms because the $L$-value dependence was small during the main phase of the storm and the difference was increased as time progresses. We have no reasonable explanation for the reason why $\mathrm{O}^{\geq 3+}$ ions were denser at a small $L$ value than at a large $L$ value. It is speculated that $\mathrm{O}^{\geq 3+}$ ions could be more directly supplied from the solar wind to the region of small $L$ value, in particular, during Storm 2. As for Storm 1, the density variation with a period of 72 hours was relatively small in magnitude, suggesting that the ion density was relatively uniformity between $L=3.5-5.0$.

\subsection{Behavior of $O$ Ions in the Near-Earth Magnetotail}

[34] Figures $2 \mathrm{c}$ and $2 \mathrm{~d}$ show that in general, the number density of $\mathrm{O}^{+}$ions in the near-Earth magnetotail was more or less correlated with that of $\mathrm{O}^{6+}$ ions. We have found no convincing explanation for the concurrent variations of them. Perhaps, the temporal variations of the $\mathrm{O}^{+}$and $\mathrm{O}^{6+}$ ion densities were largely determined by a global structure of the magnetosphere including substorm activities, rather than source and loss processes of the ions for this particular energy range of Geotail/STICS (9.27-214.6 keV/q). There was a slight increase in the number density of $\mathrm{O}^{+}$ions during the first storm that occurred from 6-7 August 1998. This increase in $\mathrm{O}^{+}$ions has been attributed to a nonadiabatic acceleration process during a substorm by Nosé et al. [2001]. For this particular storm, the number density of the $\mathrm{O}^{+,++}$ions were almost simultaneously increased in the inner magnetosphere. However, the number density of $\mathrm{O}^{+}$ ions in the near-Earth magnetotail was not increased during the latter two storms, whereas the number density of $\mathrm{O}^{+,++}$ ions were increased in the inner magnetosphere. Thus no observational evidence is, so far, provided concerning the material connection between the inner magnetosphere (Polar) and the near-Earth magnetotail (Geotail).

\section{Conclusion}

[35] Following are the major conclusions of this study.

[36] 1. From the data collected from the Polar satellite, it was found that the number densities of $\mathrm{O}^{+,++}$and $\mathrm{O}^{\geq 3+}$ ions in the inner magnetosphere were increased almost simultaneously at $L \leq 5$ during magnetic storms. The observed $\mathrm{O}^{+,++}$ions and $\mathrm{O}^{\geq 3+}$ ions were thought to originate from the Earth and the Sun, respectively.

[37] 2. This increase in the number density of highcharge-state ions in the inner magnetosphere measured by the Polar satellite can be sufficiently explained by the enhancement of the convection electric field. The enhanced convection electric field probably fed the high-charge-state $\mathrm{O}$ ions from the solar wind to the inner magnetosphere through the high-latitude magnetopause. If this was the case, the increase in the number density of $\mathrm{O}$ ions in the solar wind or the near-Earth magnetotail would not be a necessary condition for the increase in the number density of high-charge-state ions in the inner magnetosphere.

[38] 3. The number density of high-charge-state $\mathrm{O}$ ions in the near-Earth magnetotail measured by the Geotail satellite was significantly lower than that measured by the ACE in the solar wind and that measured by the Polar satellite in the inner magnetosphere. The $\mathrm{O}$ ions are thought to enter the magnetosphere through the low-latitude magnetopause and move duskward with a low energy cutoff. Therefore the number density of high-charge-state $\mathrm{O}$ ions was found to be low.

[39] Acknowledgments. The authors are grateful to Richard W. McEntire, Anthony T.Y. Lui, and Masahito Nosé for providing the Geotail/EPIC data. The Dst index was provided by WDC Kyoto. The OMNI data were obtained from the GSFC/SPDF OMNIWeb interface at http:// omniweb.gsfc.nasa.gov/. The work of Y. Ebihara was supported by the Program for Improvement of Research Environment for Young Researchers from the Special Coordination Funds for Promoting Science and Technology commissioned by the Ministry of Education, Culture, Sports, Science and Technology of Japan.

[40] Wolfgang Baumjohann thanks Q.-G. Zong and Anna Milillo for their assistance in evaluating this paper.

\section{References}

Antonova, A. E. (1996), High-latitude particle traps and related phenomena, Radiat. Meas., 26(3), 409-411.

Antonova, A. E., Yu. I. Gubar, and A. P. Kropotlin (2000), Energetic particle population in the high-latitude geomagnetosphere, Phys. Chem. Earth (C), 25(1-2), 47-50.

Ashour-Abdalla, M., et al. (1997), Ion sources and acceleration mechanisms inferred from local distribution functions, Geophys. Res. Lett., 24(8), 955-958.

Baumjohann, W., and R. A. Treumann (1997), Basic Space Plasma Physics, 120 pp., Imperial Coll. Press, London, U. K.

Blake, J. B. (1999), Comment on "Cusp: A new acceleration region of the magnetosphere" by Jiasheng Chen et al., Czech. J. Phys., 49(4a), $675-677$.

Chen, J., T. A. Fritz, R. B. Sheldon, H. Spence, W. N. Spjeldvik, J. F. Fennell, and S. Livi (1997), A new, temporarily confined population in the polar cap during the August 27, 1996 geomagnetic field distortion period, Geophys. Res. Lett., 24(12), 1447-1450.

Chen, J., T. A. Fritz, and R. B. Sheldon (2005), Comparison of energetic ions in cusp and outer radiation belt, J. Geophys. Res., 110, A12219, doi:10.1029/2004JA010718. 
Christon, S. P., D. C. Hamilton, G. Gloeckler, T. E. Eastman, and F. M. Ipavich (1994), High charge state carbon and oxygen ions in the Earth's equatorial quasi-trapping region, J. Geophys. Res., 99(A7), 13,465-13,488.

Christon, S. P., et al. (1998), Concurrent observations of solar wind oxygen by Geotail in the magnetosphere and wind in interplanetary space, Geophys. Res. Lett., 25(15), 2987-2990.

Cladis, J. B. (1986), Parallel acceleration and transport of ions from polar ionosphere to plasma sheet, Geophys. Res. Lett., 13(9), 893-896.

Daglis, I. A., G. Kasotakis, E. T. Sarris, Y. Kamide, S. Livi, and B. Wilken (1999a), Variations of the ion composition during a large magnetic storm and their consequences, Phys. Chem. Earth, 24(1-3), 229-232.

Daglis, I. A., R. M. Thorne, W. Baumjohann, and S. Orsini (1999b), Terrestrial ring current: Origin, formation, and decay, Rev. Geophys., 37(4), $407-$ 438 .

Delcourt, D. C., and J.-A. Sauvaud (1999), Populating of the cusp and boundary layers by energetic (hundreds of $\mathrm{keV}$ ) equatorial particles, J. Geophys. Res., 104(A10), 22,635-22,648.

Delcourt, D. C., J.-A. Sauvaud, and A. Pedersen (1990), Dynamics of single-particle orbits during substorm expansion phase, J. Geophys. Res., 95(A12), 20,853-20,865

Eastman, T., and S. Christon (1995), Ion composition and transport near the Earth's magnetopause, in Physics of the Magnetopause, Geophys. Monogr. Ser., vol. 90, edited by P. Song, B. U. Ô. Sonnerup, and M. F. Thomsen, pp. 131-137, AGU, Washington, D. C.

Eastman, T. E., E. A. Greene, S. P. Christon, G. Gloeckler, D. C. Hamilton, F. M. Ipavich, G. Kremser, and B. Wilken (1990), Ion composition in and near the frontside boundary layer, Geophys. Res. Lett., 17(11), 2031-2034.

Ebihara, Y., M. Yamada, S. Watanabe, and M. Ejiri (2006), Fate of outflowing suprathermal oxygen ions that originate in the polar ionosphere, J. Geophys. Res., 111, A04219, doi:10.1029/2005JA011403.

Fritz, T. A., J. Chen, and G. L. Siscoe (2003), Energetic ions, large diamagnetic cavities, and Chapman-Ferraro cusp, J. Geophys. Res., 108(A1), 1028, doi:10.1029/2002JA009476.

Gloeckler, G., B. Wilken, W. Studemann, F. M. Ipavich, D. Hovestadt, D. C Hamilton, and G. Kremser (1985), First composition measurement of the bulk of the storm-time ring current (1 to $300 \mathrm{keV} / \mathrm{e}$ ) with AMPTE-CCE, Geophys. Res. Lett., 12(5), 325-328.

Gloeckler, G., F. M. Ipavich, D. C. Hamilton, B. Wilken, W. Studemann, G. Kremser, and D. Hovestadt (1986), Solar wind carbon, nitrogen and oxygen abundances measured in the Earth's magnetosheath with AMPTE/CCE, Geophys. Res. Lett., 13(8), 793-796.

Gloeckler, G., et al. (1998), Investigation of the composition of solar and interstellar matter using solar wind and pickup ion measurements with SWICS and SWIMS on the ACE Spacecraft, Space Sci. Rev., 86(1-4), $497-539$.

Grande, M., C. H. Perry, J. B. Blake, M. W. Chen, J. F. Fennell, and B. Wilken (1996), Observations of iron, silicon, and other heavy ions in the geostationary altitude region during late March 1991, J. Geophys. Res., 101(A11), 24,707-24,718.

Hamilton, D. C., G. Gloeckler, F. M. Ipavich, W. Studemann, B. Wilken, and G. Kremser (1988), Ring current development during the great geomagnetic storm of February 1986, J. Geophys. Res., 93(A12), 14,34314,355 .

Henke, T., J. Woch, U. Mall, S. Livi, B. Wilken, R. Schwenn, G. Gloeckler, R. von Steiger, R. Forsyth, and A. Balogh (1998), Differences in the $\mathrm{O}^{7+} / \mathrm{O}^{6+}$ ratio of magnetic cloud and non-cloud coronal mass ejections, Geophys. Res. Lett., 25(18), 3465-3468.

Kavanagh, L. D., Jr., J. W. Freeman Jr., and A. J. Chen (1968), Plasma flow in the magnetosphere, J. Geophys. Res., 73(17), 5511-5519.

King, J. H., and N. E. Papitashvili (2005), Solar wind spatial scales in and comparisons of hourly wind and ACE plasma and magnetic field data, J. Geophys. Res., 110, A02104, doi:10.1029/2004JA010649.

Kremser, G., W. Studemann, B. Wilken, G. Gloeckler, D. C. Hamilton, and F. M. Ipavich (1987), Average spatial distributions of energetic O+, O2+, O6+, and C6+ ions in the magnetosphere observed by AMPTE CCE, J. Geophys. Res., 92(A5), 4459-4466.

Krimigis, S. M., G. Gloeckler, R. W. McEntire, T. A. Potemra, F. L. Scarf, and E. G. Shelley (1985), Magnetic storm of September 4, 1984: Synthesis of ring current spectra and energy densities measured with AMPTE/CCE, Geophys. Res. Lett., 12(5), 329-332.
Lie-Svendsen, Ø., and R. Esser (2005), Modeling the energy budget of solar wind minor ions: Implications for temperatures and abundances, Astrophys. J., 618(2), 1057-1073.

Lodders, K. (2003), Solar system abundances and condensation temperatures of the elements, Astrophys. J., 591(2), 1220-1247.

Moore, T. E., and J. L. Horwitz (2007), Stellar ablation of planetary atmospheres, Rev. Geophys., 45, RG3002, doi:10.1029/2005RG000194.

Nosé, M., S. Ohtani, K. Takahashi, A. T. Y. Lui, R. W. McEntire, D. J. Williams, S. P. Christon, and K. Yumoto (2001), Ion composition of the near-Earth plasma sheet in storm and quiet intervals: Geotail/EPIC measurements, J. Geophys. Res., 106(A5), 8391-8403.

Perry, C. H., M. Grande, T. H. Zurbuchen, S. Hefti, G. Gloeckler, J. F. Fennell, B. Wilken, and T. A. Fritz (2000), Use of Fe charge state changes as a tracer for solar wind entry to the magnetosphere, Geophys. Res. Lett., 27(16), 2441-2444.

Pugacheva, G. I., A. A. Gusev, U. B. Jayanthi, N. J. Schuch, and W. N. Spjeldvik (2005), Cusp region radiation belts in the dayside magnetosphere, J. Atmos. Solar Terr. Phys., 67, 479-487.

Rairden, R. L., L. A. Frank, and J. D. Craven (1986), Geocoronal imaging with dynamics explorer, J. Geophys. Res., 91(A12), 13,613-13,630.

Roeder, J. L., M. W. Chen, J. F. Fennell, and R. Friedel (2005), Empirical models of the low-energy plasma in the inner magnetosphere, Space Weather, 3, S12B06, doi:10.1029/2005SW000161.

Rosenbauer, H. H. Grunwaldt, M. D. Montgomery, G. Paschmann, and N. Sckopke (1975), Heos 2 plasma observations in the distant polar magnetosphere: The plasma mantle, J. Geophys. Res., 80(19), 2723-2737.

Sandahl, I. (2003), The cusp as a source of plasma for the magnetosphere, Adv. Space Res., 31(5), 1195-1205.

Sheldon, R. B., H. E. Spence, J. S. Sullivan, T. A. Fritz, and J. Chen (1998), The discovery of trapped energetic electrons in the outer cusp, Geophys. Res. Lett., 25(11), 1825-1828.

Shimazu, H., and T. Tanaka (2005), Simulation of entry of shock-driftaccelerated solar energetic protons into the magnetosphere, J. Geophys. Res., 110, A10105, doi:10.1029/2004JA010997.

Spjeldvik, W. N., and T. A. Fritz (1978), Theory for charge states of energetic oxygen ions in the Earth's radiation belts, J. Geophys. Res., 83(A4), 1583 1594.

Tsyganenko, N. A. (1995), Modeling the Earth's magnetospheric magnetic field confined within a realistic magnetopause, J. Geophys. Res., 100(A4), 5599-5612.

Tsyganenko, N. A., and D. P. Stern (1996), A new-generation global magnetosphere field model, based on spacecraft magnetometer data, ISTP Newsl., 6(1), 21.

Weimer, D. R. (2001), An improved model of ionospheric electric potentials including substorm perturbations and application to the Geospace Environment Modeling November 24, 1996, event, J. Geophys. Res., 106(A1), 407-416.

Wilken, B., et al. (1992), Magnetospheric ion composition spectrometer onboard the CRRES spacecraft, J. Spacecr. Rockets, 29(4), 585-591.

Williams, D. J., R. W. McEntire, C. Schlemm II, A. T. Y. Lui, G. Gloeckler, S. P. Christon, and F. Gliem (1994), Geotail energetic particles and ion composition instrument, J. Geomagn. Geoelectr., 46(1), 39-57.

Yau, A. W., and M. André (1997), Source processes in the high-latitude ionosphere, Space Sci. Rev., 80(1-2), 1-25.

Zuluaga, C. A., E. S. Beiser, J. Chen, and T. A. Fritz (2006), Implications of unusual pitch-angle distributions observed by ISEE-1 and 2, Ann. Geophys., 24(11), 3099-3113.

J. Chen and T. A. Fritz, Center for Space Physics, Boston University, 725 Commonwealth Avenue, Boston, MA 02215, USA.

Y. Ebihara, Institute for Advanced Research, Nagoya University, Furo-cho, Chikusa-ku, Nagoya, Aichi 464-8601, Japan. (ebihara@stelab.nagoya-u. ac.jp)

M. Grande, Institute of Mathematical and Physical Sciences, University of Wales, Aberystwyth, Ceredigion SY23 3BZ, UK

S. Kasahara, Institute of Space and Astronautical Science, Japan Aerospace Exploration Agency, 3-1-1 Yoshinodai, Sagamihara, Kanagawa 229-8510, Japan.

Y. Miyoshi and K. Seki, Solar-Terrestrial Environment Laboratory, Nagoya University, Furo-cho, Chikusa-ku, Nagoya, Aichi 464-8601, Japan.

T. H. Zurbuchen, Department of Atmospheric, Oceanic and Space Sciences, University of Michigan, 2455 Hayward Street, Ann Arbor, MI 48109-2143, USA. 